\title{
Building a sustainable and transferable sulphur emission free BSR
}

\author{
Gunnar Prause ${ }^{1,2}$ (D) Eunice O. Olaniyi ${ }^{1,2}$ (ID
}

Published online: 25 May 2020

(C) The Author(s) 2020

\begin{abstract}
The maritime industry is getting much attention owing to the current energy and climate crises. There are increasing discussions on sustainable maritime transport across the globe especially after the successful implementation of the sulphur regulations in the Baltic Sea Region (BSR). The world is now getting ready for the 2020 global sulphur cap suggesting that the energy transition outlook in the maritime sector is becoming clearer and there is no going back.

Still, global energy consumption is growing at an alarming rate, and all hands must remain on deck to avert possible world crises. There are still questions related to clean shipping, waste management, clean fuel, decarbonisation of fuel and greenhouse associated with global warming. What are the expected hurdles of a complete transition to a complete clean maritime transport industry? Can the world achieve total integration of this policy to contribute to environmental protection?

The study investigates the effect of both public and private cost of environmental governance in the maritime sector and evaluates the budding orchestration of green/clean shipping initiatives to activate regulatory policies using the Sulphur Emission Control Area (SECA) regulation in the Baltic state region, its state of the art, coordination and cost. The study further addresses the gaps in the present and future development of regulation compliance focussing on their design, monitoring and control to meet the global outlook for the 2020 global sulphur cap.
\end{abstract}

Keywords Clean shipping $\cdot 2020$ Global sulphur cap $\cdot$ DRY $\cdot$ Sustainability $\cdot$ Regulations

\section{Die Errichtung eines nachhaltigen und übertragbaren Ostseeraumes ohne Schwefelemissionen}

\section{State of the art}

From a technological and economical point of view, the maritime sector is regarded a complex industry that is distressed with diverse challenges ranging from high investment costs, unstable costs of fuel, geological and political issues around the world (Rack 2017). Shipping as a sector is growing rapidly because of the increased demand for transportation and because it is seen as the most cost-effective way of moving goods around and across the globe (Aas

Gunnar Prause

gunnar.prause@ taltech.ee

$\triangle$ Eunice O. Olaniyi

eunice.olaniyi@taltech.ee

1 Tallinn University of Technology, Akadeemia tee 3, 12618 Tallinn, Estonia

2 Wismar University of Applied Sciences, Philipp-Müller-Str. 14, 23966 Wismar, Germany et al. 2019). Notwithstanding, for a long time, shipping activities have produced significant amounts of harmful emission (Lindstad et al. 2015) conveying the need to curb the consequence or reduce the outcome thereof. Climate change together with the air pollution from shipping emissions thus increased environmental anxieties and rightly so, causing some dramatic change to the regulatory framework in the maritime landscape all over the world (Ren and Lützen 2015). One of such regulatory framework was proposed by the International Convention for the Prevention of Pollution from Ships (MARPOL), Annex VI on emissions and bunkering fuel requirement that regulates sulphur content in bunker fuel (Lindstad et al. 2015).

Different emissions come from shipping activities i.e. nitrogen oxides (NOx), sulphur oxides (SOx), carbon monoxide $(\mathrm{CO})$ and carbon dioxide $\left(\mathrm{CO}_{2}\right)$ and the IMO has been working tirelessly to ensure their reduction (Burel et al. 2013). However, as popularly reported (i.e. Klimont et al. 2013; Olaniyi and Viirmäe 2016) the major bunker oil for ship is the Heavy fuel oil (HFO) a residual potion of crude 
oil distillation so that at combustion, the ship engine gives off the sulphur emissions to the atmosphere necessitating limiting SOx emissions from ships to improve air quality and protect the environment especially for people living around ports and coastal area.

The establishing the Sulphur emission control (SECA) areas was, therefore, a good step undertaken by the International Maritime Organisation (IMO) to reducing sulphur emission from shipping especially around the Baltic Sea region (BSR) and North Channel (Olaniyi and Prause 2019a). Consequently, since 2015, the sulphur cap of $0.1 \%$ w/w was enacted in the BSR and North Channel and by 2020 other ships outside SECA must reduce their sulphur emission to $0.5 \% \mathrm{w} / \mathrm{w}$ (IMO 2016), implying shipowners plying all water surfaces all over the world must now comply with the sulphur rule.

Maritime shipping is a major anchor for global trade and economy and Sys et al. (2016) explained that the choice of sulphur regulation compliance will determine the strategic stance of individual shipowners. Diverse studies have reported the different alternatives considered to be economically feasible to meet the SECA regulations (Seo et al. 2016). Olaniyi and Prause (2019b) reported how shipowners in the BSR are exploring economically viable options for the SECA and the global sulphur law post-2020. In the BSR, the popular choices for ship compliance are switching from heavy fuel oil (HFO) to low sulphur fuel i.e. marine gas oil (MGO), maritime diesel oil (MDO), the ultra-low sulphur fuel (ULSFO) or compliant fuel blends which are expected to be available in the market through a different form of products, the use of the scrubber plus HFO-an abatement technology and the use of alternative fuel like the liquefied natural gas (LNG) (Lähteenmäki-Uutela et al. 2019). Noteworthy to mention that all of these approaches have their pros and cons, and different shipowners have built their compliance strategies around one or more of them with most of their decisions weighed between the capital expenditures and their resulting operational expenditure (Gu and Wallace 2017). For example, despite a lot of the negative debates on the use of the scrubbers, some shipowners would still prefer the installation of the scrubber exhaust gas cleaning systems so that they can continue to enjoy the low cost of this residual fuel (HFO) (Atari et al. 2019). Hoping to solve this critical challenge, many studies have proposed different approaches to help the choice of the compliance choices ranging from multi-criteria approach (Ren and Lützen 2015), stochastic programming (Schinas and Stefanakos2012), cost-benefit analysis (Jiang et al. 2014), costs function of emission abatement alternatives (Lindstad et al. 2015) and value at risk (VaR) analysis (Atari and Prause 2017) and the result reemphasises the importance of establishing sustainable approach for regulatory compliance (Olaniyi and Prause 2019a).
Delving further into their disadvantages using MGO and other distillates, for example, would mean a high increase in fuel cost for shipowners as well as fuel tank adaptation for the new type of fuel. This situation also implies an expensive plant upgrade (a significant increase in production costs) for fuel producers (Olaniyi 2017; Olaniyi et al. 2018a). More so, some of these new blends of fuel may have compatibility concerns making fuel handling a quality control challenge for the shipowners even though the IMO has already published a "Guidance on Best Practice for Fuel Oil Purchasers/Users for assuring the quality of fuel oil used onboard ships" (Prause et al. 2019a).

The installation of the scrubber system remains complex, especially for retrofits (Nikopoulou et al. 2013). The significant investment cost for the exhaust gas cleaning system as well as the operational cost related to increased power consumption and the possible need for chemical consumables and sludge handling for hybrid and closed-loop scrubbers are all issues shipowners must face and overcome (Olaniyi et al. 2018b, 2019a, 2019b). On a different angle entirely, the use of LNG is seen to be gaining more acceptable ground to complying for the sulphur emission law as well as for compliance for other forthcoming emission regulations (Ren and Lützen 2015). Even though the LNG bunkering infrastructure is still underdeveloped, the infrastructural growth is very rapid around the world especially in Europe (Lähteenmäki-Uutela et al. 2019; Olaniyi and Gerlitz 2019) and while the original oil-based fuels will most likely be seen as the major fuel option for most shipowners, the business opportunities for the LNG fuel will be very interesting and enticing for newly built ships around the world as the 2020 global sulphur cap infolds.

Having looked into the SECA compliance processes in the BSR, the North Sea and the English Channel in the last three years, the authors concluded that it is important to increase the visibility and awareness of this regulatory topic and to align reports to improve cleaning shipping operational know-how globally (Prause and Olaniyi 2017). The authors acknowledge diverse literature on ship emissions, however, information on the specific topic of this paper which addresses the link between emissions and economic impact is still very limited. According to Olaniyi and Prause (2018), one of the reasons why policy implementation fails is that most of the discussions only dwell on their negative impact but do not centre on the smooth transitions of the regulations into actual practice through series of observation of the costs, the impact and the implementation gap. Accordingly, for sustainable environmental policy, it is essential to study and consolidate resulting in the technological, economic or social outcome (Olaniyi et al. 2018c).

Thus, through empirical evidence and archival data, this work investigates the regulatory performance of the SECA regulation in the BSR and what lessons are learned to sus- 
tain its governance? The analysis facilitates the assessment of the role and effectiveness of the sulphur emission law. Given this context and utilizing results gathered after three years of SECA implementation in the BSR, the authors probe situations that can impede the regulatory progress come 2020. Since the study involves aggregates evaluation, many aspects of financial outcomes are also considered for shipowners to make the best compliance solution. Both quantitative and qualitative data approaches were used to collect data in the frame EU BSR Interreg Programme sponsored projects. The paper concludes with pragmatic recommendations for global regulatory visibility and sustainability.

The next section of the paper gives a summary of the methods used to gather data followed by a section that gives an overview of the SECA regulation activities in the BSR. The fourth section discusses the result through recommendations for the 2020 global cap followed by the conclusion.

\section{Methods}

Since the purpose of the study was to explore and give a description of the state of play of the compliance activities of the sulphur regulation within the maritime sector, the authors used both quantitative and qualitative method to collect and analyse the data according to Marshall (1995, pp. 78-80). As primary data collection, expert interviews, case studies, surveys and focus group meetings and workshops were used. This approach was taken to enhance, converge and corroborate the results outcomes as explained by Klein and Myers (1999).

Using Yin (1989), descriptive analysis of the interviews, focus groups and workshop meetings were made. Statistical software was used to analyse the survey data with a 5-point summative rating scales from -2 to +2 - showing the degree to which the economic impact of SECA was very negative to very positive to maritime actors in the BSR.

The Osterwalder (2004) business development model was used for compliance models aimed to reduce emissions and transaction costs of compliance using the scrubber systems and the LNG value network. Costs of regulations are categorised into regulation charges, substansive compliance costs, and administrative burden. However, only compliance and administrative burden costs are applicable to SECA. The Standard Cost Model (SCM) by Renda et al. (2013) was used to calculate the administrative burden costs of the regulation (i.e. costs incurred whenever a company is confronted by the necessity to provide information that arises by the operation of law such as the SECA). Lastly, the authors extrapolated the maritime fuel consumption of ships in BSR before and post 2015 to determine the additional
SECA-related costs proportionally distributed according to the type of compliance in the BSR.

\section{Results}

\subsection{Overview of the compliance strategies in the BSR}

Compliance measurement of air emissions on the Baltic waters had an impressive result of $95 \%$ compliance rate and $85 \%$ around the Baltic water boarders. Shipowners adopted a different strategy for compliance. While some went for a total strategy of a specific compliance method, some adopted the hybrid strategy that combines two or more of the compliance methods. The favourite choice for most shipowners is switching to the low sulphur fuel because it only slightly increases the cost of operations for a voyage and the shipowners do not necessarily have to make any investment decisions or risk undertakings. Other hybrids of low sulphur fuel are growing in demand because they are less expensive than conventional distillates.

The installation of the scrubber is mostly preferred for retrofit for old ships that are nine years and above while shipowners prefer the LNG tank installations for newly built ships. Most shipowners are still wary of this approach but the Stochastic approach (Binomial) was validated as an appropriate and promising instrument to assess and evaluate the scrubber installation process if need be (details in Atari et al. 2019). The EU Directive 2014/94/EU on TENT-T (Trans-European Transport Networks) core seaports that mandate the ports to be equipped with LNG bunkering terminals by the year 2025 facilitates the development of the LNG infrastructure across Europe.

\subsection{The economic impact of SECA regulations on maritime business activities}

The survey outcome suggests that the general economic effects are negligible for most shipowners due to the significant reduction in fuel price since 2014, however, some stakeholders like the fuel producers must make a significant adjustment in their production plants to comply. This implies that sulphur regulations are very costly and risky to small and medium fuel producer who must make heavy investment in their production to produce compliant fuel (details in Prause et al. 2019b). With a homogenous similarity in the stakeholder responses, the standard deviation analysis of the survey data, shows that SECA regulation impact on costs, pricing, FDI, cargo flows and modal splits were low while innovation and the branding of the BSR have been positively impacted by SECA. Some of these impacts are noted to be country and sector-specific. 
Table 1 Cost of SECA Compliance (millions) (2015-2018)

\begin{tabular}{lllll}
\hline & 2015 & 2016 & 2017 & 2018 \\
\hline Fuel consumption (m/ton) & 4.973 & 4.947 & 4.920 & 4.894 \\
Non-MGO/MDO & 3.978 & 3.957 & 3.936 & 3.915 \\
Mean ULS-IFO380 Spread (€) & 186.26 & 150.43 & 151.92 & 182.83 \\
Annual add. Fuel costs (million $€)$ & 615.616 & 500.641 & 502.608 & 563.940 \\
\hline
\end{tabular}

Source: authors'

Table 2 Total costs of SECA regualtions (annual)

\begin{tabular}{ll}
\hline Total annual average costs & Million $€$ \\
\hline Additional annual fuel costs & 550 \\
Annual administrative burden & 2.96 \\
Sum & 553 \\
\hline
\end{tabular}

Source: authors

In general, because there are different fragments of tasks to fulfil, it is hard to notice the administrative burden of SECA - except for the maintenance-because and each of these tasks takes only a little time on a normal operation but in sum could be time-consuming. The SECA information obligations identified as administrative burdens to shipowners are associated but not limited to recording into bunker delivery notes (BDN); time spent recording (fuel sample, scrubber emissions logbook \& waste disposal logbook (for ships using the scrubber technology), fuel switchover before entering SECA. Others are training and awareness of staff (also include hiring), off hiring days recorded during scrubber or new tank installations and maintenance, time to write applications for subsidies, grant and loans related to SECA investments and other unspecified obligations.

To calculate the administrative burden, the authors assumed average monthly wages of $5000 €$ in Denmark, Finland, Germany and Sweden as well as average monthly staff costs of $3500 €$ in Estonia, Latvia, Lithuania and Poland, the total annual costs of administrative burden for shipowners in the BSR due to SECA-related administrative burden was calculated to around 2.7 million $€$. However, if the annual administrative burden per ship is calculated (using Helcom 2018 estimation of 1500 ships), the resulting costs would be less than $2000 €$ per ship every year which can be considered as a negligible cost-block compared to other cost categories in shipping sector such as capital costs or fuel costs. Also, the total SECA-related administrative burden annually for all EU maritime authorities which mostly include compliance checks of ships in national ports was calculated to be $260,000 €$. By adding up both administrative activities equals approximately 2.96 million $€$ as the annual total cost of administrative burden in the BSR. It is important to note that these findings are lower than the pre-SECA related research report on the ex-ante expectations of SECA impact on maritime business implying that in BSR the numbers were overestimated compared to the trifling effects that appeared after 2015. This report backed up with cases from shipping lines around Europe.

Next, the costs of SECA regulations compliance was calculated using an average fuel spread per ton calculation from the year 2015 to 2018 using the Rotterdam daily fuel prices (ECG 2019). Consumed maritime fuel in 2015 was extrapolated to the following years by assuming an annual maritime traffic increase of $1.5 \%$ and an annual energy efficiency increase of $2 \%$ within the whole BSR fleet according to Kalli et al. (2013). Thus, the 2016 total fuel consumption in BSR, as well as the fuel consumption of the following years, are forecasted (Table 1) by taking the current annual fuel consumption in a million tons and multiplying it by $1.015 * 0.98$, i.e. $4.947=4.973 * 1.015 * 0.98$ (Prause and Olaniyi 2019).

The total additional costs for SECA compliance in 2015 was made by dividing the additional compliance costs by the consumed fuel in BSR in 2015 amounts to 616 million $€$. With the exact approach, the extra SECA compliance costs between 2016 and 2018 are valued as shown in Table 1:

Accordingly, by considering the median value within 2015 and 2018, the average costs are made to about 550 million $€$ for the BSR. By taking the additional total costs as well as the administrative burden of SECA regulations into account, the estimation of the total annual cost of SECA regulation is made as shown in Table 2:

Aforementioned, there are were many extrapolations of the SECA results and as expected, ordinarily regulations would always have a direct impact on the industry involved but in this case, the plummeted fuel costs since 2014 had cushion the negative effect of SECA. The introduction of sulphur regulations in the BSR was seen to have influenced the maritime companies established after 2010 in the BSR positively. Aside from maritime and offshore sectors, many of the new entrants offer different range of emission reduction technologies for both power plants and maritime engines. Although some of these companies having about 10 staff or less, they are still able to serve global markets. This particular result shows that the SECA regulation has had a positive impact on the production, application or exploitation of eco-innovations within the BSR innovation system. However, these innovations outcomes are more or less incremental in nature rather than radical. They are also new for the users as opposed to new for the world. 


\subsection{Entrepreneurial compliance options for marine fuel producers}

Although fuel costs have been low since 2014, which have reduced the burden of ship owners, the fuel producers are still under pressure to produce compliant fuel. While the bigger fuel companies have been able to successfully navigate their way around it, medium size fuel producers are struggling (Olaniyi and Viirmae 2016). To avoid the vicious cycles that could lead to precarious financial performance small and medium-size fuel producers need to take a strategic business stance through the change in their business models. Accordingly, the authors are proposing the Maritime Energy Contracting Model (MEC) model as a market mechanism that uses the Energy Supply Contract (ESC) concept using the scrubber technology where the fuel producers pre-finance the scrubber installation on contracted ships and at the same time supply HFO. Subsequently, the same concept can be used to create the LNG Maritime Energy Contracting Business Model ( $\mathrm{MEC}_{\mathrm{LNG}}$ ) (see Olaniyi and Gerlitz 2019) using the contextual idea of a project company pre-financing the LNG retrofit for a ship through a contractual agreement with shipowners for a constant supply of the LNG to protect the sulphur emission compliance. As with the MEC, the central stimulus for the $\mathrm{MEC}_{\mathrm{LNG}}$ is to lower the costs of complying with the sulphur regulations for the shipowners and increasing the business scope for the Project Company (PC).

The overall advantages of both energy business models for fuel producers and distributors can be summarised to be:

- Reduction of SOx emissions.

- Savings related to investment costs and other costs.

- Creation of jobs and careers.

- Operational costs reductions.

- Free technology and expertise backing for the shipowner.

- Flexible investment option for the fuel company.

- A higher margin for the fuel production company.

- Customised contracts.

The key activities of these models show how marine fuel producers will evolve from mare producers to service providers that will introduce compliance solutions where their major value proposition will shift from economies of scale approach to an economy of scope concept. The energy models are empirically validated with a case study of RoPax ferry ship that plies Tallinn-Helsinki route. The proposed models' advocate for small and medium companies to create a niche for themselves to boost their competitive advantage in a heavily monopolised industry.

For example, the business model package for the MEC using the scrubber is calculated by using the annual scrub- ber cost at $10 \%$ additional scrubber fuel/year., $2 \%$, additional scrubber service yearly and an annuity of 15 years depreciation of scrubber/year with a $6 \%$ interest costs. The cost is calculated as following:

MECPrice $_{t}=$ Fuelcost $_{t}+$ Scrubber costs $_{t}$

+ Adjustments $_{t}$

Where the Scrubber Costs $t=0.1 \times$ HFOCost $_{t}$

$+0.02 \times$ Scrubber Price $_{t}+$ Annuity $_{t}$

Although there are considerable gaps between commercial contracts for HFO bunker and the LNG, the authors suggest that for this adaptation to work, the energy contract should be made on short-term bases (i.e. 1-3 years) so that it slowly develops. The proposed business model has the full potential to improve fuel supply and cooperation among various maritime stakeholders.

\section{Discussion}

\subsection{What we have learned going forward}

First, we have learned that the BSR (Baltic Sea Region) and North Channel became a successful test lab for the world since 2015 January and has been very exceptional in the implementation of the sulphur regulation. The world must look into what was done, how they were done to enable and trigger a sustainable future for the sulphur law and clean shipping in general globally. Along this line, it is important the rest of the world cautiously proceed with the 2020 global sulphur rule, as each country must be able to generate country-specific strategy while drawing on the strength of knowledge carried from a different region or country. Looking into what has happened in the BSR (i.e. compliance activities, opportunities and challenges as well as the compliance costs), they need to take inventory of the current situation in their countries and draw conclusions from them. This bottom-up implementation strategy will ensure sustainability. One caution might be that even though the authors support the bottom-up approach to the sulphur regulation and that a one-plan-fits-all approach that involves a whole adaption from the BSR will not work for all countries, the authors still put forward that there are still many lessons and modus operandi to draw from the BSR experience as recorded in this study.

Second, one can expect that bunker fuel supply and availability will change after the 2020 global sulphur cap that will spur demand for drastic and cost-efficient technological. This will introduce more confusion in the market because unfortunately when there are many technological or abatement options, decisions become hard to make. To make the matter worse, already there are radical discus- 
sions on decarbonisation and other projected environmental inclined restrictions adding more chaos to the already over the flooded market. The good news is that it seems the decision to use the more expensive fuel instead of the expensive abatement options will keep the maritime-based supply chains in check in the coming years. This must be put into cognisance when choosing compliance strategies.

Third, the content and design features of the SECA rules in combination with other current and upcoming environmental rules may not be enough to make the shipping industry shift entirely to clean shipping technology. A radical or systemic innovation would require a different set of regulatory requirements that is efficient and sustainable. There is still a lot of room for improvement for knowledge on the environmental impact of ship emissions and further extension of available data on emission, on monitoring and for development of compliance methods or technology. For the emission regulations such as the sulphur emission to work, the policymakers must seek to integrate and adopt a potentially high-cost effective compliance option/approach for all actors and stakeholders.

Fourth, noting the disparity between Europe and probably North America against the rest of the world, all hands must be on deck especially with the forthcoming global sulphur 2020 regulation to ensure for all countries take responsibility by actively looking inward as China is presently doing to proffer a way out of this global challenge. A continuous reduction of global sulphur emission will influence the future climate change positively.

Further, the world cannot lose focus on other methods of sulphur emission such as from agriculture. For example in agriculture, part of the sulphur in the sulphuric acid used in the production of fertiliser goes into a biological recycle in the soil and drained into the ocean from the soil bed to the river. Other considerations are emissions from industrial waste. In other words, the introduction of ambitious stricter emission limits must be followed by actions from other sectors to stabilise sulphur emissions globally.

Again, regional sulphur limits vary and there are too many information, too many dos and don'ts that shipowners have to contend with as they move coast to coast. One of such is the amendment of the law that bans the usage of the HFO without the installation of the scrubber onboard which gives ports the authority to detain vessels with non-compliant fuel or fuel tank. Pushing this point further another law in some ports like in Germany and Belgium have already banned the use of the open-loop scrubbers within their area also constraining the discharge of the scrubber waste by doing so. These are two varying laws regarding the same technology and the same abatement solution which calls for a standard unification of law across all ports.

\section{Conclusions}

This study aggregates SECA regulations economic outcome in the BSR as the world is set to embark on the global sulphur cap from 2020. By providing the integrative economic impacts of clean shipping in the BSR, the authors support the aim of the International Convention for the Prevention of Pollution from Ships (MARPOL) Annex VI, Convention on Long-Range Transboundary Air Pollution, EU Sulphur Directive 2012/33/EU to reduce emissions and safeguard lives. This way shipowners and maritime actors and well as the policymakers can have a broader view on the overall costs and technological and entrepreneurial potentials of the regulatory compliance activities. This provides an enabler for a coping mechanism for all actors to ensure the industry's sustainability especially in view of the 2020 global sulphur rule. This type of study is useful as benchmarking and referencing tool for efficient dissemination of regulatory systems in the future.

Funding Open Access funding provided by Projekt DEAL.

Conflict of interest G. Prause and E.O. Olaniyi declare that they have no competing interests.

Open Access This article is licensed under a Creative Commons Attribution 4.0 International License, which permits use, sharing, adaptation, distribution and reproduction in any medium or format, as long as you give appropriate credit to the original author(s) and the source, provide a link to the Creative Commons licence, and indicate if changes were made. The images or other third party material in this article are included in the article's Creative Commons licence, unless indicated otherwise in a credit line to the material. If material is not included in the article's Creative Commons licence and your intended use is not permitted by statutory regulation or exceeds the permitted use, you will need to obtain permission directly from the copyright holder. To view a copy of this licence, visit http://creativecommons.org/licenses/by/4. $0 /$.

\section{References}

Aas W, Mortier A, Bowersox V, Cherian R, Faluvegi G, Fagerli H, Myhre CL et al (2019) Global and regional trends of atmospheric sulfur. Sci Rep 9(1):953

Atari S, Prause G (2017) Risk assessment of emission abatement technologies for clean shipping. In: International Conference on Reliability and Statistics in Transportation and Communication. Springer, Cham, pp 93-101

Atari S, Bakkar Y, Olaniyi EO, Prause G (2019) Real options analysis of abatement investments for sulphur emission control areas compliance. J Entrepreneursh Sustain Issues 6(3):1062-1086. https:// doi.org/10.9770/jesi.2019.6.3(1)

Burel F, Taccani R, Zuliani N (2013) Improving sustainability of maritime transport through the utilization of Liquefied Natural Gas (LNG) for propulsion. Energy 57:412-420

ECG (2019) Bunker prices. http://ecgassociation.eu/PublicationsReports/General/Fuel-Prices/Bunker-Prithiss

Gu Y, Wallace SW (2017) Scrubber: a potentially overestimated compliance method for the emission control areas: the importance of involving a ship's sailing pattern in the evaluation. Transp Res Part D Transp Environ 55:51-66 
HELCOM (2018) Maritime Assessment 2018-HELCOM Assessment on maritime activities in the Baltic Sea 2018. Baltic Sea Environment Proceedings No.152. Helsinki Commission, Helsinki, p 253

IMO (2016) IMO sets 2020 date for ships to comply with low sulphur fuel oil requirement. Press briefing release 28/10/2016. http:// www.imo.org/en/MediaCentre/PressBriefngs/Pages/MEPC-702020sulphur.aspx. Accessed 01.12.2016

Jiang L, Kronbak J, Christensen LP (2014) The costs and benefits of sulphur reduction measures: sulphur scrubbers versus marine gas oil. Transp Res Part D Transp Environ 28:19-27

Kalli J, Jalkanen JP, Johansson Repka S (2013) Atmospheric emissions of European SECA shipping: long-term projections. WMU J Marit Aff 12(2):129-145. https://doi.org/10.1007/s13437-0130050-9

Klein HK, Myers MD (1999) A set of principles for conducting and evaluating interpretive field studies in information systems. MIS Quarterly 23(1):67-93

Klimont Z, Smith SJ, Cofala J (2013) The last decade of global anthropogenic sulfur dioxide: 2000-2011 emissions. Environ Res Lett $8(1): 14003$

Lähteenmäki-Uutela A, Yliskylä-Peuralahti J, Olaniyi E, Haukioja T, Repka S, Prause G, De Andres Gonzalez O (2019) The impacts of the sulphur emission regulation on the sulphur emission abatement innovation system in the Baltic Sea region. Clean Technol Environ Policy. https://doi.org/10.1007/s10098-019-01684-2

Lindstad H, Sandaas I, Strømman AH (2015) Assessment of cost as a function of abatement options in maritime emission control areas. Transp Res Part D Transp Environ 38:41-48

Marshall C (1995) Designing qualitative research. SAGE, Thousand Oaks, London

Nikopoulou Z, Cullinane K, Jensen A (2013) The role of a cap-andtrade market in reducing $\mathrm{NO} \mathrm{x}$ and $\mathrm{SO} \mathrm{x}$ emissions: Prospects and benefits for ships within the Northern European ECA. Proceedings of the Institution of Mechanical Engineers, Part M. J Eng Marit Environ 227(2):136-154

Olaniyi EO (2017) Towards EU 2020: an outlook of SECA regulations implementation in the BSR. Balt J Eur Stud 7(2):182-207. https:// doi.org/10.1515/bjes-2017-0016

Olaniyi EO, Gerlitz L (2019) LNG Maritime energy contracting model. Entrepreneursh Sustain Issues 7(1):574-594. https://doi.org/10. 9770/jesi.2019.7.1(40)

Olaniyi E, Prause (2018) Assessment of SECA—related administrative Burden in the Baltic Sea Region. Reliability and Statistics in Transportation and Communication Conference (Relsat, 2018.), Riga

Olaniyi EO, Prause G (2019a) SECA regulatory impact assessment: administrative burden costs in the Baltic Sea Region. Transport Telecommun 20(1):62-73. https://doi.org/10.2478/ttj-2019-0006

Olaniyi EO, Prause G (2019b) A comparative study on SECA compliance options for maritime fuel producers. J Entrepreneursh Innov Emerg Econom. https://doi.org/10.1177/2393957519885521

Olaniyi EO, Viirmäe M (2016) The economic impact of environmental regulations on a maritime fuel production company. Res Econ Business Cent East Eur 8(2):58-84

Olaniyi E, Prause G, Boyesen J (2018a) The impact of SECA regulations on clean shipping in the BSR. In: Ölçer AI, Kitada M,
Dalaklis D, Ballini F (eds) Trends and challenges in maritime energy management, vol 6. Springer, Berlin Heidelberg, pp 309-323 https://doi.org/10.1007/978-3-319-74576-3

Olaniyi EO, Atari S, Prause G (2018c) Maritime energy contracting for clean shipping. Transport Telecommun 19(1):31-44. https:// doi.org/10.2478/ttj-2018-0004

Olaniyi EO, Bakkar Y, Prause G (2019a) Entrepreneurial compliance opportunities for maritime fuel producers. J Entrepreneursh Sustain Issues 6(4):1550-1565. https://doi.org/10.9770/jesi.2019.6.4(1)

Olaniyi EO, Gerber P, Prause G (2018b) Strategic energy partnership in shipping. In: Kabashkin I, Yatskiv I, Prentkovskis O (eds) Reliability and statistics in transportation and communication, vol 36. Springer, Berlin Heidelberg, pp 102-111

Osterwalder A (2004) The business model ontology — a proposition in a design science approach. http://www.hec.unil.ch/aosterwa/PhD/ Osterwalder_PhD_BM_Ontology.pdf. Accessed 10.02.2018

Prause G, Olaniyi EO (2017) The impact of environmental regulations on regional development in Eastern Estonia. In: Muravska T (ed) Proceedings of Reports The International Conference "New Challenges of Economic and Business Development-2017", Riga, May 18th-20th Latvian State University, Riga, pp 431-442

Prause G, Olaniyi EO (2019) A compliance cost analysis of the SECA regulation in the Baltic Sea. J Entrepreneursh Sustain Issues 6(4):1907-1921. https://doi.org/10.9770/jesi.2019.6.4(26)

Prause G, Reinhold K, Järvis M, Olaniyi E, Tint P (2019a) The Socio-economic impact of green shipping: a holistic view from the Baltic Sea region. In: Kabashkin I, Yatskiv I (eds) Reliability and statistics in transportation and communication. Lecture notes in networks and systems. Springer, Berlin, pp 615-624

Prause G, Tuisk T, Olaniyi EO (2019b) Between sustainability, social cohesion and security regional development in Northeastern Estonia. J Entrepreneursh Sustain Issues 6(3):1235-1254. https://doi.org/10.9770/jesi.2019.6.3(13)

Rack V (2017) Business model innovation in the oil and gas supply industry. Master's thesis, Nod university, vol 47

Ren J, Lützen M (2015) Fuzzy multi-criteria decision-making method for technology selection for emissions reduction from shipping under uncertainties. Transp Res Part D Transp Environ 40:43-60

Renda A, Schrefler L, Luchetta G, Zavatta R (2013) Assessing the costs and benefits of regulation. Centre for European Policy Studies, Brüssel (http://ec.Europa.eu/smartregulation/impact/ commission_guidelines/docs/131210_cba_study_sg_final)

Schinas O, Stefanakos CN (2012) Cost assessment of environmental regulation and options for marine operators. Transp Res Part C Emerging Technol 25:81-99

Seo S, Chu B, Noh Y, Jang W, Lee S, Seo Y, Chang D (2016) An economic evaluation of operating expenditures for LNG fuel gas supply systems onboard ocean-going ships considering availability. Ships Offshore Struct 11(2):213-223

Sys C, Vanelslander T, Adriaenssens M, Van Rillaer I (2016) International emission regulation in sea transport: economic feasibility and impact. Transp Res Part D Transp Environ 45:139-151

Yin RK (1989) Case study research: design and methods. Revised edition. Applied social research methods series, 5. SAGE, Newbury Park 